\title{
ANALISIS CAPAIAN SISTEM PENYEDIAN AIR MINUM PERDESAAN DI DESA SUMBERKIMA, BALI
}

\author{
The Analysis of the Achievements of Rural Drinking Water Supply System in \\ Sumberkima Village, Bali
}

\author{
D.K. Sudarsana \\ Teknik Sipil, Universitas Udayana, Bali \\ Email: dksudarsana@unud.ac.id
}

\begin{abstract}
The government announced a settlement infrastructure performance achievement in 2019 with $100 \%$ access to drinking water, 0\% slump, 100\% sanitary, known as 100-0-100 initiative. $M D G ' S 2015$ settlement infrastructure sectors targeted are 68-10-62. To determine the achievement of this target needs to be evaluated. In this paper specifically analyze the achievement of rural drinking water supply system (SPAMDes). Descriptive method is used in this study. Studies conducted in the village Sumberkima, District Grokgak, Bali Province. Data collected by census method. Variables to determine the indicators of access to drinking water using the terms of reference of the Ministry of Public Works. The analysis finds access of drinking water service until August 2015 reached 85\%. The achievement of the access to drinking water service is sourced from the piping connection from BUMDES 32\%, $26 \%$ of shallow wells and deep wells $27 \%$. Although the service is access to drinking water reached above the 2015 target (85\%> 68\%), but needs to be improved serviceability with access to drinking water piping connection system of BUMDES to improve the safer of quality.
\end{abstract}

Key words: settlement infrastructure, SPAMDes, achievement.

\begin{abstract}
Abstrak
Pemerintah mencanangkan capain kinerja infrastruktur permukiman pada tahun 2019 dengan akses $100 \%$ air minum $0 \%$ kumuh $100 \%$ sanitasi yang dikenal dengan prakarsa 100-0-100. Sasaran MDG'S 2015 sektor infrastruktur permukiman ini ditargetkan adalah 68-10-62. Untuk mengetahui capain target ini perlu dilakukan evaluasi. Pada paper ini secara khusus menganalisis capain system penyedian air minum perdesaan (SPAMDes). Metode diskriptif digunakan dalam penelitian ini. Studi dilakukan di desa Sumberkima, Kecamatan Grokgak, Kabupaten Buleleng, Provinsi Bali. Data dikumpulkan dengan metode sensus. Variabel-varibel untuk menentukan indikator akses layanan air minum menggunakan kerangka acuan kerja dari Kementerian Pekerjaan Umum. Hasil analisis menemukan capain layanan akses air minum sampai bulan Agustus 2015 adalah sebesar 85\%. Capaian layanan akses air minum ini bersumber dari sambungan perpipaan BUMDES 32\%, sumur dangkal 26\% dan sumur dalam $27 \%$. Walaupun layanan akses air minum yang dicapai diatas target 2015 (85\%>68\%), namun perlu ditingkatkan layan akses air minum dengan system sambungan perpipaan dari BUMDES untuk meningkatkan kualitas air minum yang lebih aman.
\end{abstract}

Kata kunci: infrastruktur permukiman, SPAMDes, capain.

\section{PENDAHULUAN}

RPJMN 2015-2019 Ditjen Cipta Karya Kementerian Pekerjaan Umum Perumahan Rakyat berkomitmen mewujudkan lingkungan permukiman yang layak huni dan berkelanjutan melalui prakarsa 100-0-100 $(100 \%$ akses air bersih, 0\% kawasan permukiman kumuh, $100 \%$ akses sanitasi layak). Sasaran Millenium Development
Goals (MDG's) 2015 sektor infrastruktur permukiman ini ditargetkan adalah 68-10-62 (Anonim, 2010; Anonim, 2013). Sampai saat ini penyediaan air bersih untuk masyarakat di Indonesia masih dihadapkan pada beberapa permasalahan yang cukup kompleks dan sampai saat ini masih belum dapat diatasi sepenuhnya (Anonim 2015a, Anonim 2015b). Salah satu masalah yang masih dihadapi sampai 
saat ini yakni masih rendahnya tingkat pelayanan air bersih untuk masyarakat. Untuk mengetahui target capain ini perlu dilakukan evaluasi.

\section{METODE PENELITIAN}

\section{Tahapan Penelitian}

Tahapan penelitian meliputi: identfikasi masalah, merumuskan masalah, pengumpulan data, kompilasi data, analisis dan pembahasan dilanjutkan menyimpulkan hasil penelitian.

\section{Pengumpulan Data}

Penelitian ini mengambil kasus di desa Sumberkima, Kecamatan Grokgak, Kabupaten Buleleng, Data primer dilakukan dengan survey langsung seperti:

1) Survey tentang sumber air bersih yang digunakan masyarakat

2) Survey tentang jumlah KK dan jiwa di desa Sumberkima.

\section{Analisis Data}

Metode deskripstif digunakan untuk memenjelaskan karakteristik penduduk, geografis, lingkungan fisik daerah studi. Analisis kinerja layanan akses air bersih, kekumuhan dan sanitasi dianalisis dengan rumusan dikembangkan Direktorat Jendral Cipta Karya Kementerian Pekerjaan Umum. Untuk menghitung kinerja layanan penyediaan air minum seperti pada rumusan (1) (Prasetio, 2014).

$$
\begin{array}{lc} 
& \text { Masyarakat terlayani (jiwa) } \\
\text { Akses Air } & =- \text { Jumlah Total Masyarakat (jiwa) }_{\text {Minum }}
\end{array}
$$

\section{HASIL DAN PEMBAHASAN}

Desa Sumberkima terdiri dari 8 dusun yaitu Dusun Sumber Pao, Sumber Bunga, Taman Ayun, Taman, Sumber Kesambi, Pegametan, Tegal Sari dan Mandar Sari. Kompilasi hasil survey per Agustus 2015, ditemukan jumlah Kepala Keluarga (KK) adalah $1.402 \mathrm{KK}$. Sebaran jumlah KK ini di 8 dusun disajikan pada Gambar 1.

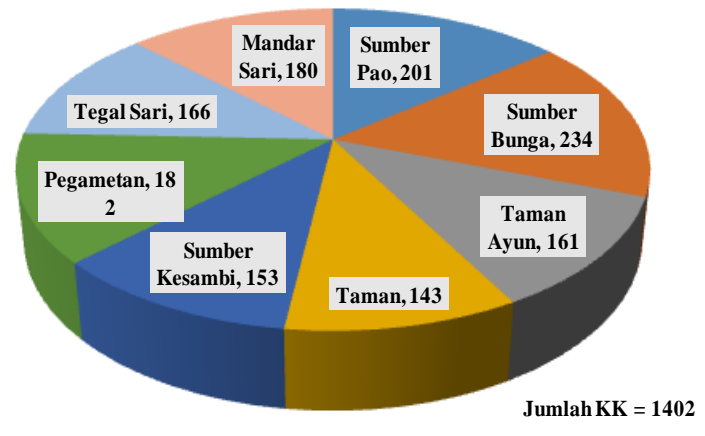

Gambar 1. Sebaran Jumlah KK di 8 dusun di desa Sumberkima per Agustus 2015

Jumlah penduduk yang ditemukan sebanyak 9.367 jiwa. Sebaran jumlah penduduk di 8 dusun didesa Sumberkima ini disajikan pada Gambar 2.

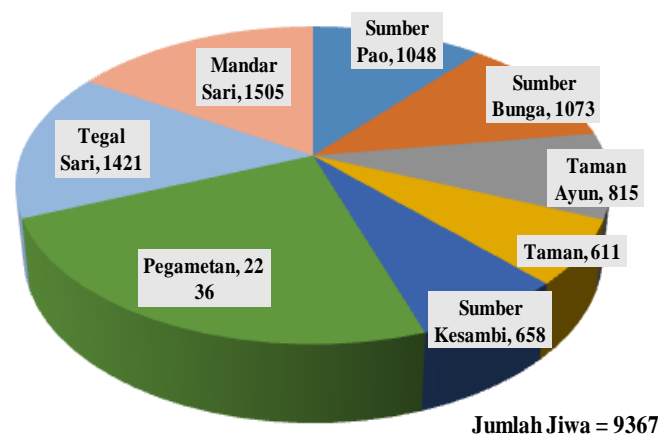

Gambar 2. Sebaran Jumlah penduduk di 8 dusun di desa Sumberkima per Agustus 2015.

Ada 4 sumber air bersih yang digunakan masyarakat yaitu:

- Bersumber dari 2 buah sumur bor dengan system aliran perpipaan menggunakan sambungan rumah (SR) yang dilengkapi dengan meteran air (water meter) yang dikelola oleh Badan Usaha Masyararakat Desa (BUMDES). Sampai Agustus 2015 masyarakat di desa Sumberkima sudah mendapatkan akses layanan air bersih dengan sistem SR dari BUMDES. Prosentase tingkat layanan dimasingmasing dusun berbeda-beda, hal ini dilihat pada Gambar 3. Pada Gambar 3 juga dapat dilihat rata-rata tingkat layanan air bersih dengan SR dari BUMDES adalah $31,64 \%$. Masyarakat yang menggunakan akses SR ini umumnya rumahnya berada dijalur perpipaan SPAM yang dikelola BUMDES. 


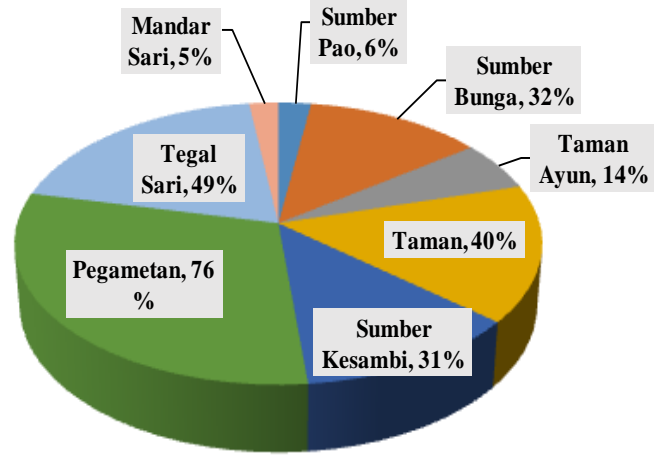

Akses Layanan dengan SR dari BUMDES rata-rata = $31.64 \%$

Gambar 3. Prosentase layanaan akses air bersih dengan system SR dari BUMDES di desa Sumberkima per Agustus 2015

- Bersumber dari Sumur yang diusahakan masyararakat. Akses air bersih dari sumur ini dapat berupa sumur dalam yaitu kedalaman sumur $>10 \mathrm{~m}$ dan sumur dangkal dengan kedalaman $<10 \mathrm{~m}$. Prosentase akses air besih masyarakat yang bersumber dari sumur dalam mencapai rata-rata $27,13 \%$ (dapat dilihat pada Gambar 4. Sedangkan rata-rata akses air bersih bersumber dari sumur dangkal mencapai $26,13 \%$. Sedangkan bersumber dari sumur dangkal adalah rata-rata $26,13 \%$. Sumber air dari sumur sebagai air bersih umumnya digunakan oleh masyarakat disekitar pesisir.

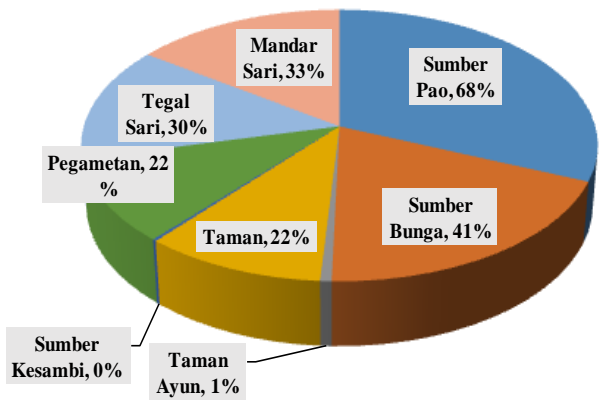

Akses Layanan Bersumber dari Sumur Dalam rata-rata $=\mathbf{2 7 . 1 3} \%$

Gambar 4. Prosentase layanaan akses air bersih Sumur Dalam di desa Sumberkima per Agustus 2015

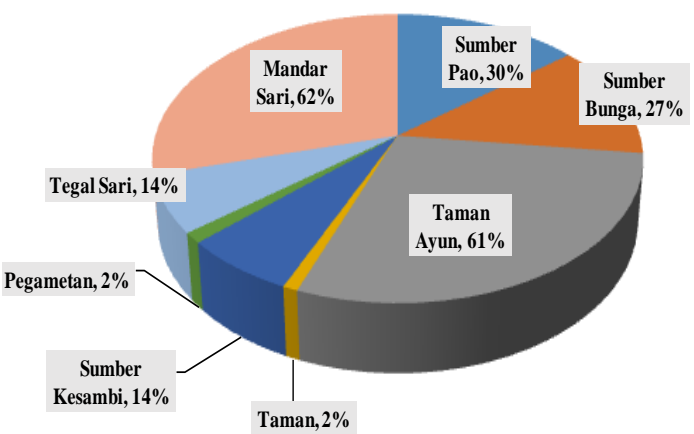

Akses Layanan Bersumber dari Sumur Dangkal rata-rata= 26.13\%

Gambar 5. Prosentase layanaan akses air bersih Sumur Dangkal di desa Sumberkima per Agustus 2015

- Bersumber dari mata air sekitar permukiman masyarakat. Prosesntase masyararakat yang mengakses air bersih besumber dari mata air rata-rata adalah mencapai $14,84 \%$, hal ini dapat dilihat pada Gambar 6. Masyarakat yang mengakses air bersih dari sumber mata air umumnya berada dilokasi agak jauh dari pesisir dan belum tersedianya sambungan perpipipaan dari Sistem Penyedian Minum (SPAM) BUMDES. Akses masyarakat yang menggunakan sumber mata air ummnua tidak mendapatkan air secara koninu dan debit air yang belum mencukupi sehingga dilakukan upaya cara menampung dimasing-masing rumah.

Prosentase masyarakat yang masih menngunakan sumber mata air dapat dilihat pada Gambar 6. Prosentase ini belum dikategorikan masyarakat terlayani akses air besih.

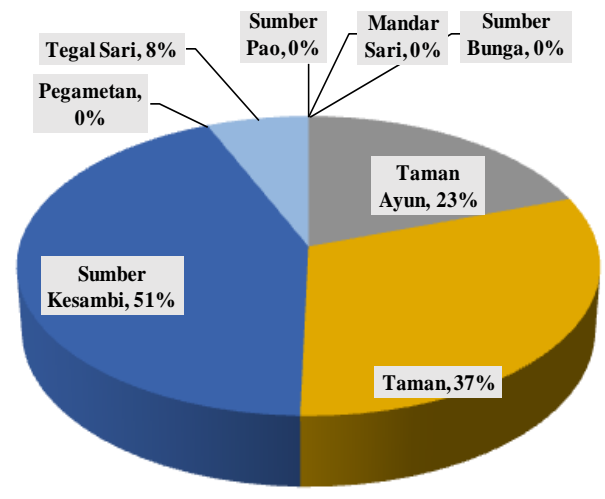

Akses Layanan Bersumber dari Mata Air rata-rata $=\mathbf{1 4 . 8 4} \%$

. Gambar 6. Prosentase akses air bersih dari Mata Air di desa Sumberkima per Agustus 2015 
Dari pembahasan diatas capain layanan akses air bersih secara koninu per Agustus 2015 mencapai $85 \%$, yang bersumber dari sambungan rumah (SR) perpipaan dari SPAM BUMDES $31,64 \%$, sumur dangkal 26,47\% dan sumur dalam $27,13 \%$. Hal ini dapat dilihat pada Gambar 7.

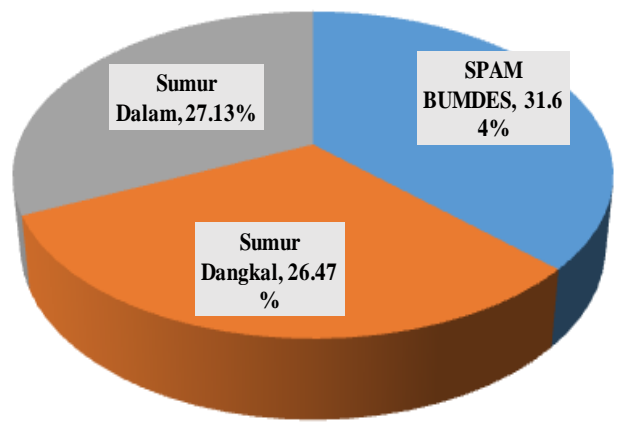

Akses Air Bersih secara kontu dari 3 sumber $=85,24 \%$

Gambar 7. Prosentase akses air bersih secara koninu dari 3 sumber air di desa Sumberkima per Agustus 2015

\section{KESIMPULAN DAN SARAN}

\section{Kesimpulan}

Hasil evaluasi menemukan capain gerakan universal akses air bersih di desa Sumberkima mencapai $85 \%$. Pencapaian ini melebihi target MDG's 2015 sebesar 68\% (capaian 85\%. > target),

\section{Saran}

Dari pencapaian akses air minum $85 \%$, hanya 31,64\% masyarakat desa Sumberkima mendapatkan akses air minum dari sisitem perpipaan dengan sambungan rumah dari SPAM yang dikelola BUMDES. Pada paper ini disarankan untuk mencari solusi agar masyarakat mendapatkan akses air bersih dari system perpipaan dari BUMDES, untuk medapatkan kualitas sumber air yang aman, terutama masyarakat yang menngunakan sumber air dari mata air dan sumur dangkal.

\section{DAFTAR PUSTAKA}

Anonim. 2010. Rencana Strategis Direktorat Jenderal Cipta Karya Tahun 20102014.

Anonim. 2013. Peraturan Menteri Pekerjaan Umum Nomor: 13/PRT/M/2013 Tentang Kebijakan dan Strategi Nasional Pengembangan Sistem Penyediaan Air Minum.

Hari Prasetio.2014. Draft Kerangka Acuan Capain Target 100-0-100 Skala Kelurahan /Desa dan Kawasan. http://www.slideshare.net/Ihza/kerang ka-acuan-pengukuran-kinerja-target100-0100-djck-kementerianpu? related $=1$

Anonim. 2015a. Matrix Program Pemberdayaan Masyarakat di Perkotaan Tahun 2015-2019. Direktorat Cipta Karya, Kementrian Pekerjaan Umum.

Anonim. 2015b. Program Peningkatan Kualitas Permukiman di Perkotaan (P2KP - Kota) Dalam Upaya Pencapaian Target 100-0-100 dan Percepatan Penanganan Kumuh di Perkotaan Tahun 2015 - 2019. http://www.slideshare.net/ariefrahadi/ 20150505-pedoman-p2-kp-kota-1000100-tahun-20152019? related $=2$ 